\title{
Multicentric Epithelioid Hemangioendothelioma Involving the Same Lower Extremity: A Case Report and Review of Literature
}

\author{
Qingjun Liu*, Jianyun Miao*, Kejian Lian, Lianshui Huang, Zhenqi Ding ${ }^{\circledR}$ \\ Department of Orthopaedic Surgery, the Affiliated Southeast Hospital of Xiamen University, Orthopaedic Trauma Center of \\ PLA, Zhangzhou, 363000, PR China.
}

* Qingjun Liu and Jianyun Miao contributed equally to the work.

$\triangle$ Corresponding author: Zhenqi Ding, M.D. 268 Zhang-Hua Road, Zhangzhou, 363000, Fujian Province, China. Tel \& Fax: +86-596-2931538; E-mail: 773594860@qq.com

(ㅇ Ivyspring International Publisher. This is an open-access article distributed under the terms of the Creative Commons License (http://creativecommons.org/ licenses/by-nc-nd/3.0/). Reproduction is permitted for personal, noncommercial use, provided that the article is in whole, unmodified, and properly cited.

Received: 2011.08.07; Accepted: 2011.09.12; Published: 2011.09.22

\begin{abstract}
Epithelioid hemangioendothelioma (EH) is an uncommon low-grade malignant soft-tissue tumor; no case has been previously reported where multicentric epithelioid hemangioendothelioma occurred in the same lower extremity at different sites. We report a case involving the common peroneal nerve and subsequently the long bone and the short bones of the same lower extremity, and also review the literature. After establishing case of several lesions, we reviewed the histopathology properly and followed up the patient for a long time with serial whole body assessment to pick up any subsequent lesions.
\end{abstract}

Key words: lower extremity, epithelioid hemangioendothelioma, multicentric

\section{Introduction}

Epithelioid hemangioendothelioma $(\mathrm{EH})$ is a rare vascular soft tissue tumor of intermediate malignancy between hemangioma and angiosarcoma in terms of frequent local recurrences and metastatic potential $^{[1]}$. Although initially described most common in the soft tissues, other frequent sites include viscera and long bone have been well reported, for example, the liver, lung, femur, tibia and humerus ${ }^{[2-4]}$. Involvement of various types of bone and soft tissue by $\mathrm{EH}$ is rare ${ }^{[5]}$. There have been no formal case reports about the epithelioid hemangioendothelioma with involvement of the different site in the same lower extremity. Here, we reported one such case and discussed its clinicopathological features, pathogenesis and treatment with literature review.

\section{Case report}

A 59-year-old female patient visited our orthopaedics clinic with complaints of increasing swelling, pain, anesthesia of the left lateral lower leg and ex- tension loss of the left great toe of six months duration. On physical examination a $2.0 \mathrm{~cm}$ mass showing tender and palpable was located on the posterolateral aspect of the proximal lower leg, appearing to arise from the left fibular head. A positive Tinel sign at the proximal fibula led us to suspect compressive neuropathy of the peroneal nerve. Radiographs showed a lytic lesion causing irregular cortical bone thinning in the body of the upper fibula with a surrounding slight soft tissue swelling (Figure $\mathbf{1} \mathbf{A})$. Then we made further both lower extremities X-ray examination, found the similar osteolytic lesion in the distal tibia and cuboid bone (Figure 1 B,C). Routine blood laboratory data were within normal limits at the time and the patient had no previous history of tumor and family history of tumor. However, magnetic resonance image (MRI) for left lower extremity manifested multiple solid lesions in the gastrocnemius muscle at the level of the head of the fibula and multifocal lesion with irregular borders at the upper fibula, distal tibia, cu- 
boid bone and calcaneus (Figure 2). Right lower extremity and other parts of the left lower extremity were apparently normal. The chest radiograph was normal. Histopathological examination of the needle aspiration biopsies from cuboid bone and tibia showed a neoplastic infiltration composed of vascular structures of different caliber lined with mild atypical endothelial cells in a myxoid stroma. The epithelioid cytomorphology were polygonal or spindle shaped, which had vesicular nuclei, unapparent nucleoli and eosinophilic cytoplasm with intractyloplasmic vacuoles and were easily identified (Figure 3). Immunohistochemical study showed immunoreactivity for SMA, CD31, CD34, CD68 and vimentin. No immunoreaction was observed for epithelial membrane antigen (EMA). Owing to these findings; there was not much doubt that the patient was diagnosed as multifocal epithelioid hemangioendothelioma.

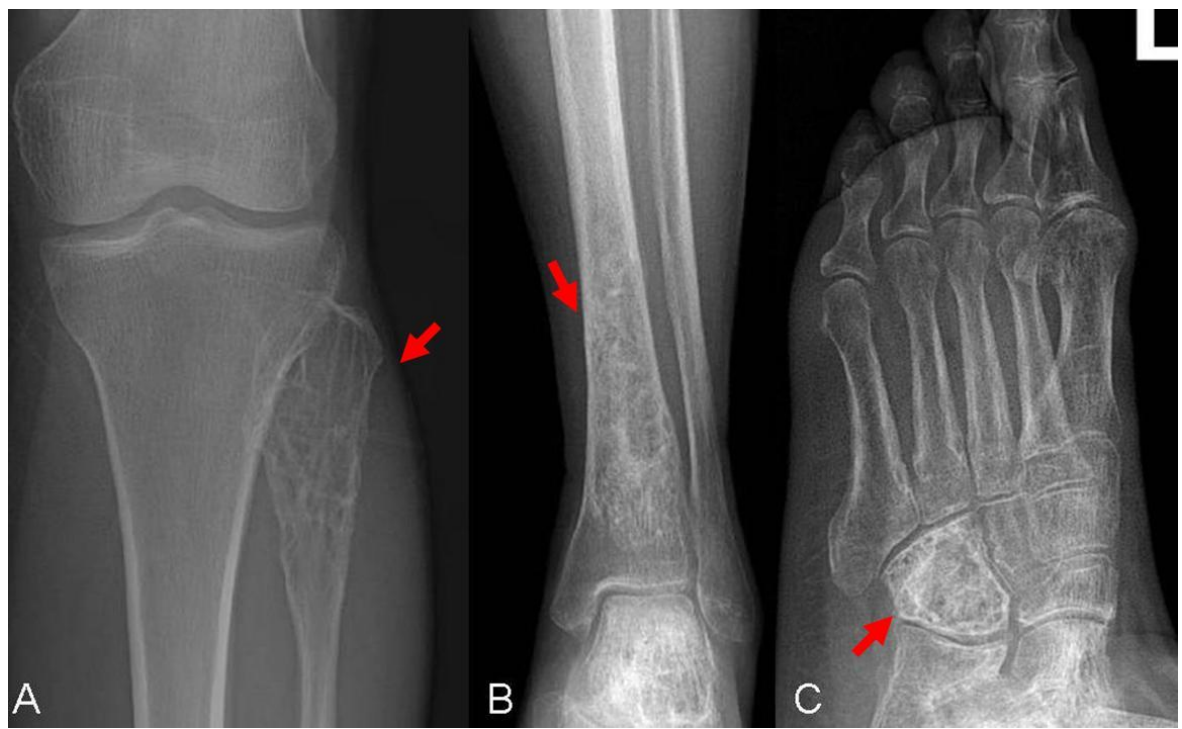

Figure I. X-rays (anterior view) of the left tibia and foot show osteolytic lesion causing irregular cortical bone in the cuboid bone, distal tibia and fibular head with a surrounding slight soft tissue swelling (arrow).

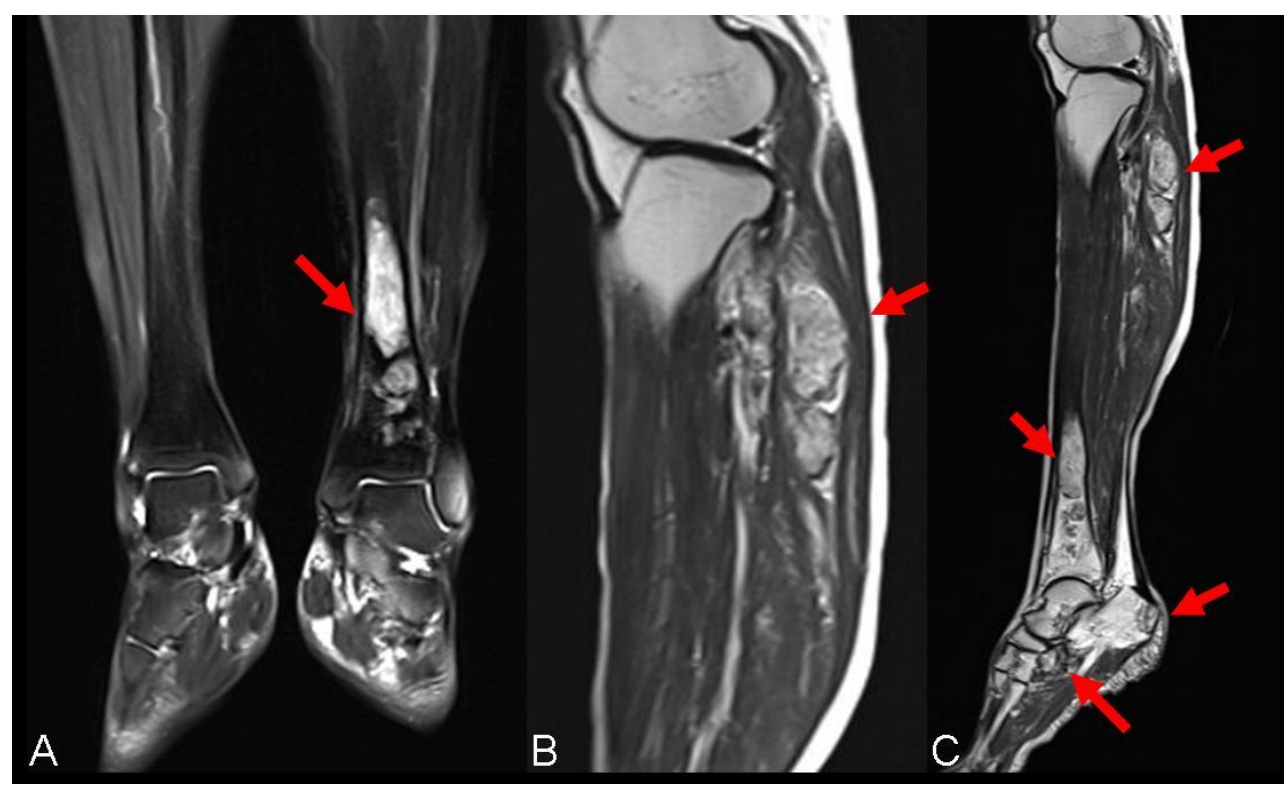

Figure 2. Presurgical MRI examinations. A: MRI showed intramedullary solid lesion covering the distal tibia bone without breaking articular surfaces. T2 weighted image showed the lesion as a high signal (arrow). B: MRI manifested multiple independent solid lesions in the gastrocnemius muscle at the level of the head of the fibula and multifocal lesion with irregular borders at the upper fibula (arrow). C:MRI examination of left lower leg revealed the occult lesions of calcaneus close to the calcaneal tubercle (arrow). 


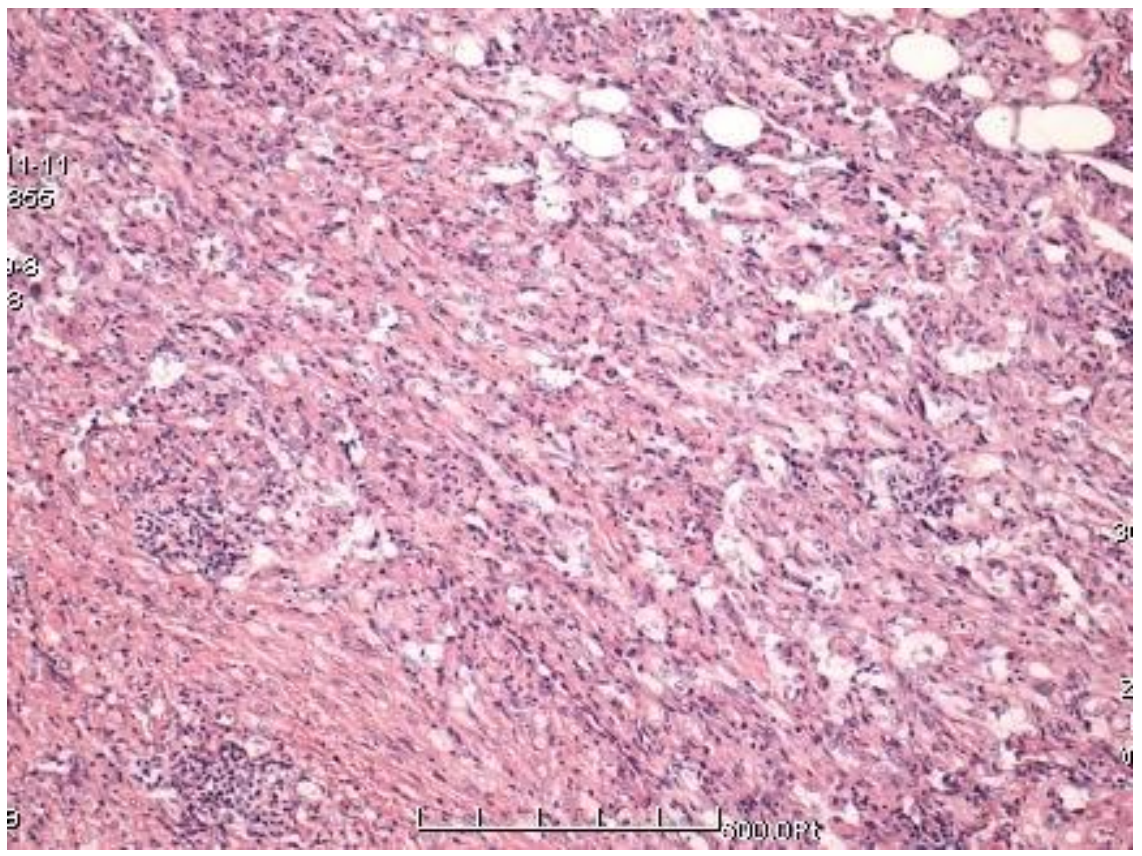

Figure 3. The lesions compose of vascular structures of different caliber lined with mild atypical endothelial cells. Histopathological picture consistent with EH (HE XI00).

Fibular head resection and curettage of other parts of the left lower extremity lesions with allogeneic bone particles filling were performed; curettage using sharp curet was done and subsequently supplemented with chemical cautery by using phenol solution. Symptoms of the peroneal nerve entrapment include anesthesia and extension loss were relieved through the removal of EH lesions. The resected soft tissue and bone lesions sent for pathologic examination were measured $5.5 \times 3.0 \times 1.5 \mathrm{~cm}$ and $6.5 \times 3.5 \times 2.5$ $\mathrm{cm}$. The hematoxylin eosin stained the tissue section after decalcification revealed tumor tissue showing the same characteristics with the previous biopsy results. The postoperative course was uneventful. At 28 months after surgery without further therapy, no local recurrence or internal organ metastasis were observed.

\section{Discussion}

The term epithelioid hemangioendothelioma was first definitively described for a vascular neoplasm of soft tissue in 1982 by Weiss and Enzinger ${ }^{[6]}$. At that time, they recognized that the clinical behavior of these tumors was neither completely benign nor fully malignant and used the term "hemangioendothelioma" to reflect metastatic potential intermediate malignancy between hemangioma and angiosarcoma. In Deyrup et al's recent report of 49 cases of EH, originating from the soft tissue mostly occur between the ages of 9 and 93 (mean age, 49 yr.), and affects the sexes equally ${ }^{[7]}$. Similar to $\mathrm{EH}$ in soft tissue, EH of bone has been encountered in virtually all age groups and can be multicentric, although it appears to peak both during the second and third decades and again in the later decades of life ${ }^{[4,8]}$. Tsuneyoshi et al. ${ }^{[9]} \mathrm{ob}-$ served that the next most frequent characteristic pattern of $\mathrm{EH}$ was a lytic lesion with variable degrees of peripheral cortication, and although it may affect any portion of the skeleton, it tends to involve bones of a particular anatomical area. In their review of the literature, Abrahams et $\mathrm{al}^{[8]}$ found that the lesions are distributed throughout the skeleton with a predilection for involvement of the calvaria, axial skeleton and lower extremity. Involvement of multiple bones has been showed a tendency to develop in the lower extremities ${ }^{[10]}$. In 2008, Deyrup et al ${ }^{[11]}$ reported 49 cases of EH of soft tissues in total, and the majority of cases are associated with low mortality, but some metastasize and cause patient death. Many other sites of involvement of bones and soft tissues are possible, such as the maxilla, spine region, the head and neck region, but to our knowledge, only few cases have been reported $^{[12-17]}$. When there is lower extremity involvement, multicentric epithelioid hemangioendothelioma has been known to involve the femur, tibia, phalange, cuneiform, tarsal navicular and metatarsal bone either as the first or subsequent tumor but multiple involvement of bones and soft tissue in the same lower extremity is very rare (Table $\mathbf{1})^{[5,18-23]}$. 
Table I. Literature review of multicentric epithelioid hemangioendothelioma with lower extremity involvement

\begin{tabular}{|c|c|c|c|c|c|c|}
\hline Authors & Year & $\begin{array}{l}\text { Number } \\
\text { of cases }\end{array}$ & Age & Male/Female & $\begin{array}{l}\text { Number } \\
\text { of lesions }\end{array}$ & Bones involved \\
\hline McNamara et al & 1993 & 1 & 61 & $\mathrm{M}$ & 4 & $\begin{array}{l}\text { distal femur, tibia, third metatarsal bone, fifth metatarsal } \\
\text { bone }\end{array}$ \\
\hline Boutin et al & 1996 & 1 & 24 & M & 10 & $\begin{array}{l}\text { proximal and distal } \\
\text { phalanges of the great toe, first metatarsal, medial cunei- } \\
\text { form, tarsal navicular, C2 and C3 vertebral } \\
\text { body, clavicle, scapulae, ilium, }\end{array}$ \\
\hline Kilpatrick et al & 1998 & 1 & 39 & M & 1 & proximal tibial \\
\hline Ignacio et al & 1999 & 1 & 41 & $\mathrm{M}$ & 3 & distal femur and patella, tibia \\
\hline Rosenthal et al & 2001 & 1 & 21 & $\mathrm{~F}$ & 4 & $\begin{array}{l}\text { fourth metatarsal, fifth metatarsal, proximal fifth phalanx, } \\
\text { left tibia }\end{array}$ \\
\hline Charfi et al & 2005 & 1 & 54 & M & 1 & left femur \\
\hline Kabukcuoglu et al & 2006 & 1 & 48 & $\mathrm{~F}$ & 2 & first metatarsal bone, left tibia \\
\hline
\end{tabular}

The peroneal nerve is a branch of the sciatic nerve, which passes behind the biceps femoris muscle and superficial to the lateral head of gastrocnemius. The peroneal nerve courses distally around the fibular neck, which makes it vulnerable to entrapment. EH originating from the lateral head of gastrocnemius is still unclear whether separate lesions represent multicentric disease or metastases, although it is multifocal in more than $50 \%$ of cases $^{[24]}$.

Controversy regarding the pathogenesis of multicentric EH exists to date. Various mechanisms have been described including metastatic spread, malignant transformation and one time multi-focal formation $^{[5,25,26]}$. However, there is little known about the biologic behavior of $\mathrm{EH}^{[26]}$. The majority of $\mathrm{EH}$ cases are associated with low mortality, but some metastasize and cause patient death ${ }^{[27]}$. Tumors that initially appeared as histologically benign, but then progressed to metastatic disease have been well documented ${ }^{[28]}$. Theurillat et al. ${ }^{[26]}$ also reported a case that a patient suffering from a vascular neoplasm with initial manifestation in the pelvis and subsequent development of lesions of $\mathrm{EH}$ in the spleen, liver, and lung during a ten-year course of disease, and then they assumed that involvement of visceral organs was caused by metastatic spread because of some genes expression. Therefore, we began to believe this hypothesis that $\mathrm{EH}$ does not represent a distinct entity, but rather an intermediate state of endothelial dedifferentiation with highly variable and unpredictable prognosis. In the present case, although we have not discovered that the multicentric EH occurred at different times (usually longer gap) or within a short period of time (simultaneously), no visceral involvement or lymph node metastasis will appear to have a good prognosis.

Synchronous involvement of adjacent bones is common, but in some cases, completely separate synchronous foci are present in anatomically distant sites. Epithelioid hemangioendothelioma is the most aggressive member of hemangioendothelioma group with metastatic potential ${ }^{[29]}$.

The differential diagnosis of $\mathrm{EH}$ primarily depends upon the site of origin of the tumor includes epithelioid hemangioma of bone, metastatic carcinoma, and epithelioid sarcoma. Epithelioid hemangioma of bone also contains epithelioid endothelial cells that are large and cuboidal with eosinophilic cytoplasm. However, in epithelioid hemangioma, well developed vascular channels are observed,in contrast to the primitive vascular channels differentiation seen in EH. The hyalinized or myxoid is also typical of EH, which is not usually observed in epithelioid hemangioma. Besides, epithelioid hemangioma of the bone is always a benign course and less likely to be multifo$\mathrm{cal}^{[30]}$. Most metastatic carcinoma to soft tissue or bone show exceedingly greater nuclear atypia and increased mitotic activity than that usually observed in $\mathrm{EH}^{[20]}$. The apparent desmoplastic reaction of metastatic carcinoma, and the positive immunoreaction with endothelial antigens in $\mathrm{EH}$ are useful features in the differential diagnosis. In Kleer et al.'s ${ }^{[4]}$ report of 40 cases of EH, two cases were excluded because follow-up showed that they represented metastatic carcinoma. The epithelioid sarcoma may cause problem in differential diagnosis. Epithelioid sarcoma generally occurs in young adults and most often involves the distal extremities with cutaneous ulceration; in this type of tumors, very typical nodulars composed of round epithelioid cells are seen, which surround central cores of necrotic debris and collagen; the vascular channels are usually observed as irregular sinusoidal channels, and necrosis is common ${ }^{[5]}$. In difficult cases, the results of immunohistochemistry have been recognized for a useful adjunct for differential diagnosis of $\mathrm{EH}$. Both metastatic carcinoma and epi- 
thelioid sarcoma typically strongly express cytokeratin. Most cases of EH show diffuse and strong immunopositivity for vimentin and some endothelial markers such as factor VIII,CD31 and CD34, and immunohistochemical analysis identifies the metastatic carcinoma cells in the absence of reactivity for endothelial markers ${ }^{[31]}$. However, some authors have reported that EH also expressed cytokeratin ${ }^{[32]}$. Thus, cytokeratin expression cannot always give an exclusive diagnosis of $\mathrm{EH}$. In the present case, the tumor cells were stained diffusely and intensely with antibodies to vimentin, showing immunoreactivity for factor VIII, CD31, CD 34 and SMA. No staining was observed with cytokeratin, S-100 and EMA.

Although $\mathrm{EH}$ is a rare tumor of vascular origin, the treatment method is based on general oncological principles $^{[28]}$. Some authors have been closely studied the pathobiologic behavior of $\mathrm{EH}$ occurring in the lung, liver, soft tissue, and bone, which indicate that the behavior and metastatic potential of $\mathrm{EH}$ vary greatly, seeming to depend upon its origin ${ }^{[9,28,29,33,34]}$. In their report of $\mathrm{EH}$ of bone, Kleer et al. ${ }^{[4]}$ also believed that the presence of visceral involvement appears indicative of a poor prognosis, regardless of the primary origin of the tumor. In their report of $\mathrm{EH}$, Weiss et al. found that the mortality associated with $\mathrm{EH}$ is $13 \%$ in soft tissue disease, $35 \%$ in liver disease, and $65 \%$ in lung disease after a minimum of 4 years of follow-up; metastatic disease occurred in approximately $20 \%$ of patients with soft tissue disease ${ }^{[28]}$. Ellis et al. reviewed the literature on $\mathrm{EH}$ and suggested that benign lesions should undergo complete and wide local excision without the need of adjuvant treatment; malignant lesions should be treated similarly to other high-grade sarcomatous lesions, using wide local excision and possible chemotherapy ${ }^{[35]}$. In addition, several studies have suggested that multifocal lesions have a better prognosis than unifocal ones ${ }^{[9,36]}$. In one series of multifocal tumors, all the patients were alive and well many years after diagnosis $^{[9]}$. Moreover, the patients with $\mathrm{EH}$ may show partial spontaneous regression in number and size ${ }^{[37]}$. Thus, in the present case, we excised the gastrocnemius $\mathrm{EH}$ and multifocal lesions of bone involving the same lower limb with an osteotome together, which was not followed by radiation or chemotherapy. In our experience, if the tumor is accessible for resection and there are no multiple organs metastasis, radical resection is a useful treatment of choice. Although radiation therapy alone has been effective in some patients with multicentric tumors, the potential complications of this treatment must be considered. For EH lesions involving multiple bones or parenchymal organs, chemotherapy is an accepted option, despite the role of chemotherapy is not clear ${ }^{[10]}$. Besides, in view of the high incidence of multifocal lesions of EH, further imaging studies should be performed, especially a complete skeletal survey.

In addition, the survival rate of $\mathrm{EH}$ patients is not only with treatment-related, but also with the nature of the tumor itself. Owing to the historical association of the term malignant EH, Deyrup et al. proposed that $\mathrm{EH}$ be categorized as low risk and high risk for aggressive behavior, on the basis of mitotic activity and tumor size ${ }^{[7]}$. In the present case, because of the wide resection achieved and the low aggressiveness of the lesion, no adjuvant therapy was decided, and 6 years after there are no signs of recurrence or metastasis.

\section{Conclusion}

$\mathrm{EH}$ involving the same lower limb includes soft tissue and bones without the parenchymal organs metastasis has rare been reported, although it represents a rare vasoformative tumor that has been more frequently identified over the past twenty years. $\mathrm{EH}$ can mimick either benign or malignant conditions with unpredictable behavior, thus early diagnosis and early treatment are particularly important. In addition, imaging strives to be comprehensive because of the high incidence of multifocal lesions, any metastatic lesion should not be missed; moreover, cell immunohistochemistry plays a meaningful role in providing for an accurate diagnosis and the different diagnosis in cases of $\mathrm{EH}$ to further guide the clinical treatment. Although no therapeutic modality other than surgery is effective in $\mathrm{EH}$, some patients can take to assist in the treatment of chemotherapy or radiation therapy for metastatic disease. However, we still cannot define the role and timing of adjuvant therapy after initial surgical resection, close follow-up is really an effective means of preventing tumor recurrence.

\section{Conflict of Interest}

The authors have declared that no conflict of interest exists.

\section{References}

[1] Gill R, O'Donnell RJ, Horvai A. Utility of immunohistochemistry for endothelial markers in distinguishing epithelioid hemangioendothelioma from carcinoma metastatic to bone. Arch Pathol Lab Med. 2009. 133(6): 967-72.

[2] Bruegel M, Muenzel D, Waldt S, Specht K, Rummeny EJ. Hepatic epithelioid hemangioendothelioma: findings at $\mathrm{CT}$ and MRI including preliminary observations at diffusion-weighted echo-planar imaging. Abdom Imaging. 2011 Aug;36(4):415-24 .

[3] Jinghong $X$, Lirong C. Pulmonary epithelioid hemangioendothelioma accompanied by bilateral multiple calcified nodules in lung. Diagn Pathol. 2011. 6: 21. 
[4] Kleer CG, Unni KK, McLeod RA. Epithelioid hemangioendothelioma of bone. Am J Surg Pathol. 1996. 20(11): 1301-11.

[5] Kabukcuoglu F, Kabukcuoglu Y, Livaoglu A, Ozagari A, Armagan R, Kuzgun U. [Epithelioid hemangioendothelioma of bone]. Acta Orthop Traumatol Turc. 2006. 40(4): 324-8.

[6] Weiss SW, Enzinger FM. Epithelioid hemangioendothelioma: a vascular tumor often mistaken for a carcinoma. Cancer. 1982. 50(5): 970-81.

[7] Deyrup AT, Tighiouart M, Montag AG, Weiss SW. Epithelioid hemangioendothelioma of soft tissue: a proposal for risk stratification based on 49 cases. Am J Surg Pathol. 2008. 32(6): 924-7.

[8] Abrahams TG, Bula W, Jones M. Epithelioid hemangioendothelioma of bone. A report of two cases and review of the literature. Skeletal Radiol. 1992. 21(8): 509-13.

[9] Tsuneyoshi M, Dorfman HD, Bauer TW. Epithelioid hemangioendothelioma of bone. A clinicopathologic, ultrastructural, and immunohistochemical study. Am J Surg Pathol. 1986. 10(11): 754-64.

[10]Boutin RD, Spaeth HJ, Mangalik A, Sell JJ. Epithelioid hemangioendothelioma of bone. Skeletal Radiol. 1996. 25(4): 391-5.

[11]Deyrup AT, Tighiouart M, Montag AG, Weiss SW. Epithelioid hemangioendothelioma of soft tissue: a proposal for risk stratification based on 49 cases. Am J Surg Pathol. 2008. 32(6): 924-7.

[12] Ramer MA, Lumerman H, Kopp W, Fisher KS, Cohen SA. Epithelioid hemangioendothelioma of the maxilla: case report and review of literature. Periodontal Clin Investig. 2001. 23(1): 31-5.

[13]Faust J, Schmidt M, Eysel P, Wanitschke R. [Epithelioid hemangioendothelioma of the spine]. Med Klin (Munich). 2001. 96(12): 740-4.

[14]Tseng CC, Tsay SH, Tsai TL, Shu CH. Epithelioid hemangioendothelioma of the nasal cavity. J Chin Med Assoc. 2005. 68(1): 45-8.

[15]Naqvi J, Ordonez NG, Luna MA, Williams MD, Weber RS, El-Naggar AK. Epithelioid hemangioendothelioma of the head and neck: role of podoplanin in the differential diagnosis. Head Neck Pathol. 2008. 2(1): 25-30.

[16] Bottini DJ, Gentile P, Ascenzi P, Galante V, Ricci A, Cervelli V. Epithelioid hemangioendothelioma of the facial bone. J Craniofac Surg. 2010. 21(6): 1994-6.

[17]Gokhan GA, Akyuz M, Gurer IE, Tuncer R. Epithelioid hemangioendothelioma derived from the spine region: case report and review of the literature. Wien Klin Wochenschr. 2006. 118(11-12): 358-61.

[18] McNamara D, Beauregard GC, Lemieux RJ. Scintigraphic "doughnut sign" on skeletal imaging due to a hemangioendothelioma of bone. J Nucl Med. 1993. 34(2): 297-300.

[19] Boutin RD, Spaeth HJ, Mangalik A, Sell JJ. Epithelioid hemangioendothelioma of bone. Skeletal Radiol. 1996. 25(4): 391-5.

[20] Kilpatrick SE, Koplyay PD, Ward WG, 2nd RF. Epithelioid hemangioendothelioma of bone and soft tissue: a fine-needle aspiration biopsy study with histologic and immunohistochemical confirmation. Diagn Cytopathol. 1998. 19(1): 38-43.

[21] Ignacio EA, Palmer KM, Mathur SC, Schwartz AM, Olan WJ. Epithelioid hemangioendothelioma of the lower extremity. Radiographics. 1999. 19(2): 531-7.

[22] Rosenthal DI, Treat ME, Mankin HJ, Rosenberg AE, Jennings CL. Treatment of epithelioid hemangioendothelioma of bone using a novel combined approach. Skeletal Radiol. 2001. 30(4): 219-22.

[23] Charfi L, Mrad K, Karray S, et al. [Epithelioid hemangioendothelioma of bone complicated by femoral fracture]. Rev Chir Orthop Reparatrice Appar Mot. 2005. 91(8): 788-91.

[24] Evans HL, Raymond AK, Ayala AG. Vascular tumors of bone: A study of 17 cases other than ordinary hemangioma, with an evaluation of the relationship of hemangioendothelioma of bone to epithelioid hemangioma, epithelioid hemangioendo- thelioma, and high-grade angiosarcoma. Hum Pathol. 2003. 34(7): 680-9.

[25]Evans HL, Raymond AK, Ayala AG. Vascular tumors of bone: A study of 17 cases other than ordinary hemangioma, with an evaluation of the relationship of hemangioendothelioma of bone to epithelioid hemangioma, epithelioid hemangioendothelioma, and high-grade angiosarcoma. Hum Pathol. 2003. 34(7): 680-9.

[26] Theurillat JP, Vavricka SR, Went P, et al. Morphologic changes and altered gene expression in an epithelioid hemangioendothelioma during a ten-year course of disease. Pathol Res Pract. 2003. 199(3): 165-70.

[27] Yanagawa H, Hashimoto $Y$, Bando $H$, Takishita $Y$, Nagano T. Intravascular bronchioloalveolar tumor with skin metastases. Chest. 1994. 105(6): 1882-4.

[28] Weiss SW, Ishak KG, Dail DH, Sweet DE, Enzinger FM. Epithelioid hemangioendothelioma and related lesions. Semin Diagn Pathol. 1986. 3(4): 259-87.

[29] Weiss SW, Enzinger FM. Epithelioid hemangioendothelioma: a vascular tumor often mistaken for a carcinoma. Cancer. 1982. 50(5): 970-81.

[30] O'Connell JX, Kattapuram SV, Mankin HJ, Bhan AK, Rosenberg AE. Epithelioid hemangioma of bone. A tumor often mistaken for low-grade angiosarcoma or malignant hemangioendothelioma. Am J Surg Pathol. 1993. 17(6): 610-7.

[31] Themistocleous GS, Papagelopoulos PJ, Petraki KD, Stilianessi EV, Partsinevelos AA, Sapkas GS. A 23-year-old woman with complete paraplegia and anesthesia below the T8 level. Clin Orthop Relat Res. 2005. (430): 258-65.

[32] Gray MH, Rosenberg AE, Dickersin GR, Bhan AK. Cytokeratin expression in epithelioid vascular neoplasms. Hum Pathol. 1990. 21(2): 212-7.

[33]Dail DH, Liebow AA, Gmelich JT, et al. Intravascular, bronchiolar, and alveolar tumor of the lung (IVBAT). An analysis of twenty cases of a peculiar sclerosing endothelial tumor. Cancer. 1983. 51(3): 452-64

[34]Dietze O, Davies SE, Williams R, Portmann B. Malignant epithelioid haemangioendothelioma of the liver: a clinicopathological and histochemical study of 12 cases. Histopathology. 1989. 15(3): 225-37.

[35]Ellis TS, Schwartz A, Starr JK, Riedel CJ. Epithelioid hemangioendothelioma of the lumbar vertebral column: case report and review of literature. Neurosurgery. 1996. 38(2): 402-7.

[36] Campanacci M, Boriani S, Giunti A. Hemangioendothelioma of bone: a study of 29 cases. Cancer. 1980. 46(4): 804-14.

[37] Kitaichi M, Nagai S, Nishimura K, et al. Pulmonary epithelioid haemangioendothelioma in 21 patients, including three with partial spontaneous regression. Eur Respir J. 1998. 12(1): 89-96. 